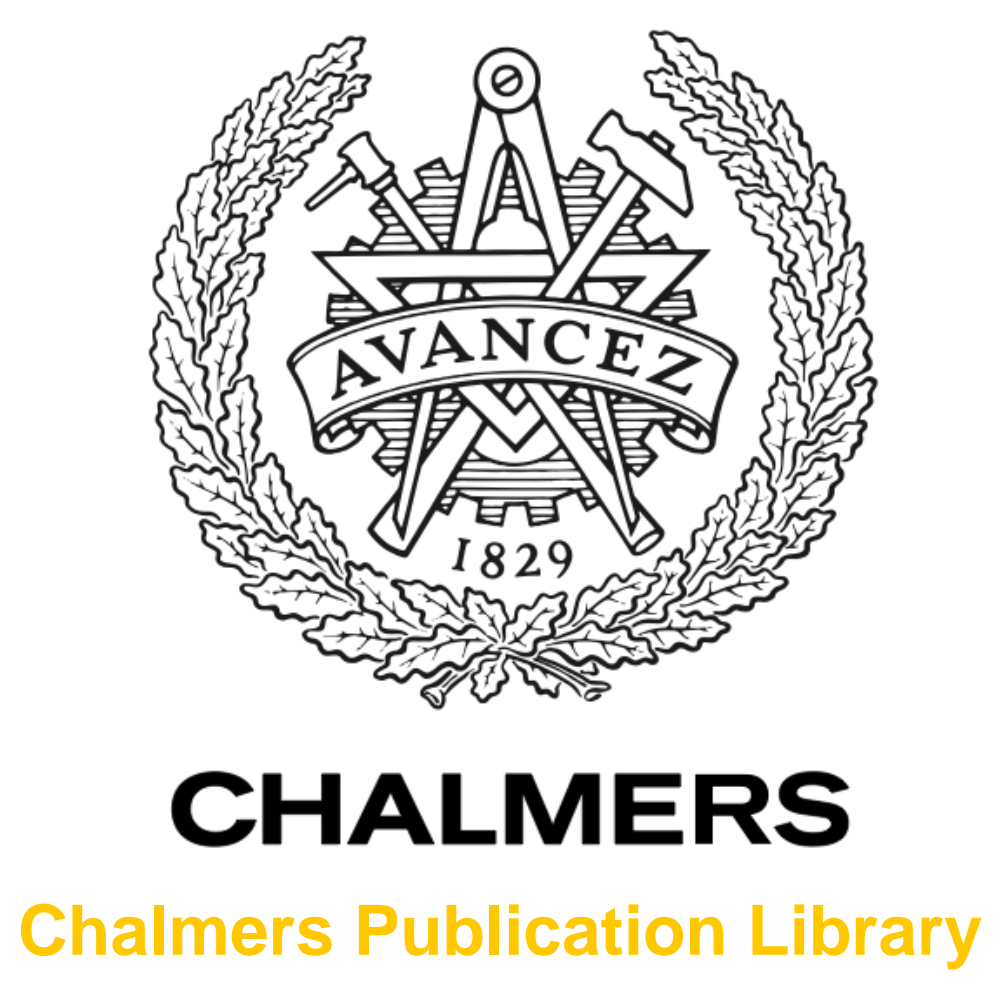

\title{
Distribution of ELF magnetic fields in Swedish dwellings
}

This document has been downloaded from Chalmers Publication Library (CPL). It is the author's version of a work that was accepted for publication in:

30th URSI General Assembly and Scientific Symposium, URSIGASS 2011, Istanbul, 13-20

\section{August 2011}

Citation for the published paper:

Hamnerius, Y. ; Atefi, S. ; Eslami, A. (2011) "Distribution of ELF magnetic fields in

Swedish dwellings". 30th URSI General Assembly and Scientific Symposium, URSIGASS

2011, Istanbul, 13-20 August 2011

http://dx.doi.org/10.1109/URSIGASS.2011.605131

Down「oaded from: http://publications.lib.chalmers.se/publication/150851

Notice: Changes introduced as a result of publishing processes such as copy-editing and formatting may not be reflected in this document. For a definitive version of this work, please refer to the published source. Please note that access to the published version might require a subscription.

Chalmers Publication Library (CPL) offers the possibility of retrieving research publications produced at Chalmers University of Technology. It covers all types of publications: articles, dissertations, licentiate theses, masters theses, conference papers, reports etc. Since 2006 it is the official tool for Chalmers official publication statistics. To ensure that Chalmers research results are disseminated as widely as possible, an Open Access Policy has been adopted.

The CPL service is administrated and maintained by Chalmers Library. 


\title{
Distribution of ELF magnetic fields in Swedish dwellings
}

\author{
Yngve Hamnerius ${ }^{1}$, Seyedreza Atefi ${ }^{2}$, Abbas Eslami ${ }^{3}$, Modesty Hopeson $^{4}$, Ashraf Khan ${ }^{5}$, Gaddy Silva $^{6}$, and Jimmy \\ Estenberg $^{7}$ \\ ${ }^{1}$ Chalmers University of Technology, Dept. of Signals \& Systems, SE-412 96 Goteborg, Sweden, \\ yngve.hamnerius@chalmers.se, ${ }^{2}$ atefi@student.chalmers.se, ${ }^{3}$ eslami@student.chalmers.se, ${ }^{4}$ modestyh@gmail.com, \\ 5ashrafk@student.chalmers.se,6rgaddy@student.chalmers.se
}

${ }^{7}$ Swedish Radiation Safety Authority, SE-171 16 Stockholm, Sweden, jimmy.estenberg@ssm.se

\begin{abstract}
The purpose of this study is to assess the distribution of magnetic fields in the frequency range $10 \mathrm{~Hz}-2000 \mathrm{~Hz}$ in randomly selected Swedish dwellings. The fields were measured in up to 3 rooms in each residence. In the master bedroom a $24 \mathrm{~h}$ logging of the fields was performed. The results show that $89 \%$ of the measured houses have average magnetic fields below $0.2 \mu \mathrm{T}$ with mean value of $0.11 \mu \mathrm{T}$ and median value $0.05 \mu \mathrm{T}$. The comparison of magnetic fields in urban and rural area show that the lowest fields were found in rural areas with $97 \%$ of the residences have average magnetic fields below $0.2 \mu \mathrm{T}$ with median value $0.04 \mu \mathrm{T}$. Comparing villas and apartments show that the median magnetic fields value for apartments is $0.07 \mu \mathrm{T}$ compared to $0.04 \mu \mathrm{T}$ for villas. The dominating frequency of the magnetic field was $50 \mathrm{~Hz}$. The total harmonic distortion (THD) of the magnetic field was measured; the median value of THD was $10.3 \%$.
\end{abstract}

\section{Introduction}

Epidemiological studies have shown a statistical association between residential magnetic fields and childhood leukaemia [1]. IARC has classified ELF magnetic fields as a possible human carcinogen [2]. The Swedish authorities have published a precautionary principle saying "If measures generally reducing exposure can be taken at reasonable cost and consequences in all other respects, an effort should be made to reduce fields radically deviating from what could be deemed normal in the environment concerned" [3]. This raises the question what is normal exposure. The magnetic fields in houses are to a high degree dependent on the electric system. The electric systems varies between different countries, therefore data from one country cannot be directly applied in another country. The main part of Swedish houses has four-conductor system with combined neutral and protective earth wire. The combination of the neutral and protective earth conductor means that return currents, which are supposed to go in the neutral conductor, also can flow in metal structures, which are connected to the protective earth. These stray currents, which often go in water and heating pipes, are major sources to magnetic fields.

The purpose of this study is to assess the distribution of magnetic fields in the frequency range $10 \mathrm{~Hz}-2000 \mathrm{~Hz}$, in randomly selected Swedish dwellings. The fields were measured in up to 3 rooms in each residence. In the master bedroom a $24 \mathrm{~h}$ logging of the fields was performed. Residences in apartments and villas as well as residences in both urban and rural areas have been assessed. The amplitude and amount of harmonics in the fields has been measured.

\section{Measurement Participants and Procedure}

A participant address register was provided by Lars Barregård, Dept. Occupational and Environmental Medicine, Sahlgrenska University Hospital and University of Gothenburg. The persons had been chosen by random in earlier studies, performed by the Dept. Occupational and Environmental Medicine and these addresses were re-used in this study. The addresses were in Göteborg, Borås and Mark. If the persons had moved within the region and we could identify the new address, the new address was used. The address register contained totally 179 addresses. We were able to get permission to perform measurements at 97 addresses. We were not able to get in contact with 38 addresses, which in most cases depended on that the person had moved, without an identifiable new address.

Three models of magnetic field meters, with logging abilities, were used in the study (given with the used frequency range): EnviroMentor ML $1(30 \mathrm{~Hz}-2000 \mathrm{~Hz})$, Combinova MFM $10(5 \mathrm{~Hz}-2000 \mathrm{~Hz})$ and Combinova 
MFM $3000(10 \mathrm{~Hz}-400 \mathrm{kHz})$. Before performing any measurements, all the instruments were calibrated in a Helmholtz coil set up, at the Swedish Radiation Safety Authority.

The EnviroMentor ML 1 was the default instrument for the $24 \mathrm{~h}$ logging in the master bedroom, except in the case that the house was close $(<200 \mathrm{~m})$ from an electric railway. In this case the Combinova MF 10 instrument was used, as its frequency range includes the power frequency $16.7 \mathrm{~Hz}$ of Swedish railways. The measurement point was positioned under the bed, avoiding close proximity to local field sources such as power adapters. The sampling rate was every $40 \mathrm{~s}$ for the EnviroMentor ML 1 logger and every $60 \mathrm{~s}$ for the Combinova MFM 10 logger.

Point measurements were performed in the kitchen, living room and master bedroom (if these rooms existed) using the Combinova MFM 3000. This instrument is more advanced; that besides giving the total RMS value for the magnetic field it also gives the amplitude of largest and second largest frequency components. Single point measurements were done close to the four corners and at the centre of the room. These point measurements were done at 3 height levels; at floor level, $80 \mathrm{~cm}$ above the floor and $160 \mathrm{~cm}$ above the floor.

In order to estimate a typical exposure of a resident, an adjusted magnetic field value was calculated, reflecting estimated time spent in different rooms. The following formulas were used to obtain the adjusted average field

3 rooms: $\boldsymbol{B}_{\text {adjust }}=\boldsymbol{B}_{\text {bed }} *\left(9 * B_{\text {sleep } R}+2 * B_{\text {kitchen }}+4 * B_{\text {livingR }}\right) /\left(15 * B_{\text {sleepR }}\right)$

2 rooms: $\quad B_{\text {adjust }}=B_{\text {bed }} *\left(13 * B_{\text {sleep } R}+2 * B_{\text {kitchen }}\right) /\left(15 * B_{\text {sleepR }}\right)$

1 room: $\quad \boldsymbol{B}_{\text {adjust }}=\boldsymbol{B}_{\text {bed }}$

$\mathrm{B}_{\text {bed }}=24 \mathrm{~h}$ average from the logging in a measurement point under the bed, $\mathrm{B}_{\text {sleepR }}=$ Room average for sleeping room, $\mathrm{B}_{\text {kitchen }}=$ Room average for kitchen and $\mathrm{B}_{\text {livingR }}=$ Room average for living room. $\mathrm{B}_{\text {sleepR, }} \mathrm{B}_{\text {kitchen, }} \mathrm{B}_{\text {livingR, were obtained }}$ from the average of 15 point measurements in each room. We chose a "typical" person spending 9 hours in bedroom, 2 hours in kitchen and 4 hours in living room.

We calculated the total harmonic distortion THD as: $\boldsymbol{T H D}=\left(\left(\boldsymbol{B}_{R M S}\right)^{2}-\left(\boldsymbol{B}_{L S}\right)^{2}\right) /\left(\boldsymbol{B}_{L S}\right)^{2}$

Where $B_{R M S}=$ Root mean square of the total magnetic field and $B_{L S}=$ the RMS amplitude of the largest frequency component.

\section{Results}

The cumulative distribution of the adjusted average value of the magnetic field in 97 houses is shown in Figure 1. We can observe that average adjusted MF is below $0.2 \mu \mathrm{T}$ in $89 \%$ of the houses. Around $7 \%$ of the houses have $\mathrm{B}_{\text {Adjust }}$ between $0.2-0.4 \mu \mathrm{T}$. The mean value of $\mathrm{B}_{\text {Adjust }}$ is $0.11 \mu \mathrm{T}$ and median value is $0.05 \mu \mathrm{T}$.

If we calculated a flat average, without weighing for time spent in different rooms, the result was very similar with values below $0.2 \mu \mathrm{T}$ in almost $91 \%$ of the dwellings. Around $5 \%$ of the houses have a flat average between 0.2 $0.4 \mu \mathrm{T}$. The mean value of the flat average is $0.10 \mu \mathrm{T}$ and median value is $0.05 \mu \mathrm{T}$.

The measurements were performed in three areas, Göteborg (population 514 000), Borås (population 101 000) and Mark (mostly rural), see table 1 . Of the total 97 dwellings, 28 were apartments and 69 were villas. The median value of $\mathrm{B}_{\mathrm{Adjust}}$ for apartments was $0.07 \mu \mathrm{T}$ and the mean was $0.17 \mu \mathrm{T}$, the median value for villas was $0.04 \mu \mathrm{T}$ and the mean was $0.09 \mu \mathrm{T}$. The point measurements were performed in three levels in each room. After calculating average RMS in each level, for each room, it was found that for most residences the floor level had the highest magnetic field.

The cumulative distribution of the average THD of the measured magnetic field is shown in figure 2. A high pass filter at $10 \mathrm{~Hz}$ was introduced for the measurements, to avoid of spurious signals from movements in the earth magnetic field. THD measurements done before this filter was introduced were discharged. We can see that around $63 \%$ of the dwellings have a THD $<20 \%$ and $85 \%$ of houses have THD $<46 \%$, the median value of THD is $10.3 \%$. 


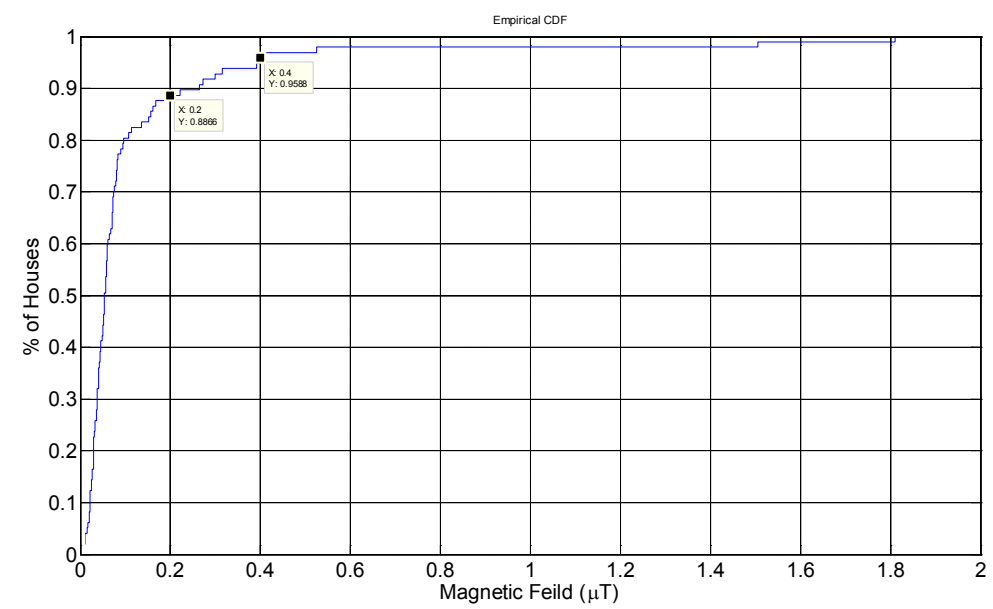

Figure 1. Cumulative distribution of the adjusted average value of the magnetic field in 97 houses.

\begin{tabular}{|c|c|c|c|}
\hline Area & Göteborg & Borås & Mark \\
\hline No of dwellings & 38 & 27 & 31 \\
\hline \% of Houses $<0.2 \mu \mathrm{T}$ & 87 & 85 & 93 \\
\hline Median & $0.05 \mu \mathrm{T}$ & $0.07 \mu \mathrm{T}$ & $0.04 \mu \mathrm{T}$ \\
\hline Mean & $0.10 \mu \mathrm{T}$ & $0.15 \mu \mathrm{T}$ & $0.09 \mu \mathrm{T}$ \\
\hline
\end{tabular}

Table 1. Comparison of the adjusted average value of the magnetic field in different areas.

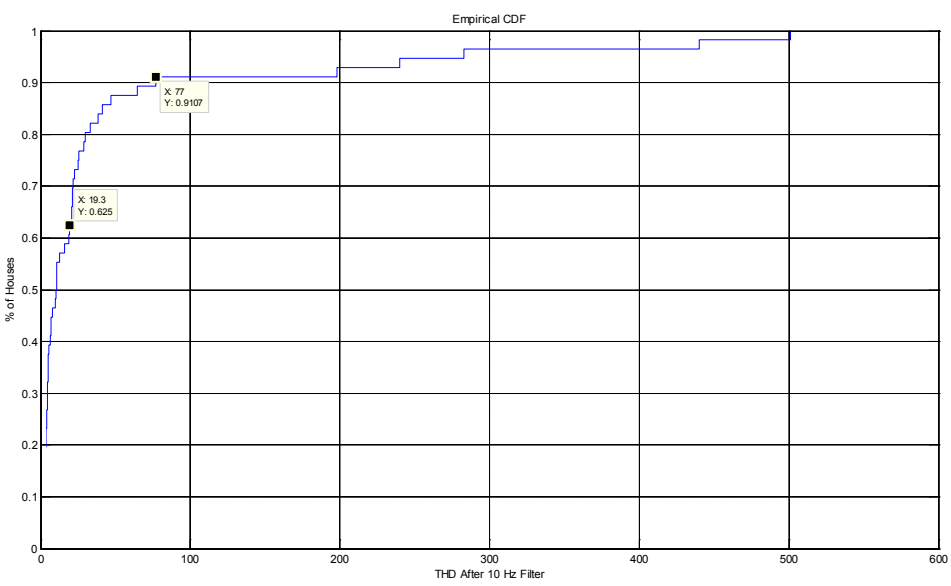

Figure 2. Cumulative distribution of average THD of the magnetic field.

\section{Discussion}

The distribution of magnetic field in 97 randomly selected dwellings showed a mean value of $\mathrm{B}_{\text {Adjust }}$ of $0.11 \mu \mathrm{T}$ and median value of $0.05 \mu \mathrm{T}$. The average adjusted magnetic field was below $0.2 \mu \mathrm{T}$ in $89 \%$ of the houses. Less than 5 $\%$ of the houses have $\mathrm{B}_{\text {Adjust }}$ above $0.4 \mu \mathrm{T}$. The magnetic fields were measured during $24 \mathrm{~h}$, which gives a time average of more than 2000 measurement values in each dwelling. These measured values were than adjusted for spatial 
variations of the magnetic fields in 3 rooms. We calculated an adjusted average magnetic field in order to estimate the exposure of a "typical" person spending estimated time in different rooms. We also calculated a flat average without weighing the time spent in different rooms. The resulting magnetic field averages calculated with these two methods turned out to be very similar. As can be seen from Figure 1 the absolute majority of the dwellings have average magnetic fields below $0.1 \mu \mathrm{T}$ with a few dwellings having considerably higher values (maximum average value was $1.81 \mu \mathrm{T})$. This means that the distribution of average magnetic field values is skew, which is illustrated by the difference between the mean and median value. With 97 measured average magnetic fields the median magnetic field value ought to be a good estimate of the typical Swedish residential exposure. The mean value is probably a less good estimate, as this value is quite sensitive to the measurement values of a few dwellings with the high levels. The result of the percentage of houses above $0.4 \mu \mathrm{T}$ should be taken with caution, as this number is building on small sample.

The exposure in villas was lower than in apartments, which probably due to less density of sources in villas. In an apartment the currents to the neighbor apartments can pass in cables in the walls. We have in earlier measurements seen a tendency that flats on lower floor levels shows higher magnetic fields, than flats on higher floor levels, in the same building. The highest magnetic field levels were most commonly on the floor level, indicating that the major sources were below the floor. The power distribution to houses in Sweden is normally via underground cables. In the case of stray currents, when part of the return current goes another way, than via the distribution cables, resulting magnetic fields will be found around the cables as well as close to the conductors of the stray currents. In some houses the higher levels on the floor was due to electric floor heating. In some houses single wire floor heating was used, which gives considerable magnetic fields. The measurements were done during the autumn of 2010, when heating was used.

If we compare the measured average magnetic fields in three areas (Göteborg, Borås and Mark) we see that the levels are comparable, with the lowest values in the rural area Mark, which is probably due to a higher proportion of villas. Borås and Göteborg, which are mostly urban areas, showed slightly higher levels, with the highest level in the measured residences in Borås.

The measured THD varied quite a lot between different dwelling, probably reflecting different use of non-linear loads, such as florescent lights, switched power supplies and electronic power regulation.

\section{Conclusion}

Our study indicates that the majority of the Swedish dwellings have average magnetic fields below $0.1 \mu \mathrm{T}$, with just a few percent above the level $0.4 \mu \mathrm{T}$, where a static association with childhood leukemia have been found in epidemiologic studies [1]. Villas had on an average lower magnetic field than apartments.

\section{Acknowledgments}

Financial support for this study was given by the Swedish Radiation Safety Authority. We want to thank all the participants, which let us in to their homes for doing measurements. The selection of study addresses made available by Professor Lars Barregård, is gratefully acknowledged.

\section{References}

1. A. Ahlbom, N. Day, M. Feychting, E. Roman, J. Skinner, J. Dockerty, M. Linet, M. McBride, J. Michaelis, JH. Olsen, T. Tynes, and PK. Verkasalo, "A pooled analysis of magnetic fields and childhood leukaemia," Br J Cancer, 83(5), Sept 2000, pp.692-698.

2. WHO IARC "IARC Monographs on the evaluation of Carcinogenic risks to humans - Non-Ionizing Radiation, Part 1: Static and Extremely Low-Frequency (ELF) Electric and Magnetic Fields”, IARC Monographs Volume 80, 2002

3. Swedish Authorities "Low Frequency Electric and Magnetic Fields: the Precautionary Principle for National Authorities" Arbetsmiljoverket et al. Report ADI 478, 1996 